\title{
Residual Neuromuscular Blockade: A Persistent Clinical Problem
}

\author{
Richard M. Pino, MD, PhD
}

The muscle relaxants have been singled out from the other agents and technics for particular discussion because of their newness, because of their greatly increasing use, and because their employment appears to be associated with certain anesthetic hazards not yet entirely clear, nor completely appreciated. ${ }^{1}$

In the classic study of deaths associated with anesthesia and surgery, Beecher and Todd ${ }^{1}$ in 1954 reported a 6 -fold increase in the death rate of patients undergoing general anesthesia when "curare" was used compared with anesthesia without neuromuscular blockade (NMB). Their study must be viewed in the context of the initial use of neuromuscular blocking drugs (NMBDs) (curare) with volatile anesthetics such as cyclopropane, ether, and trichloroethylene, and the absence of capnography, pulse oximetry, and electrocardiography, which are now the standard of care. The first routine method for monitoring the depth and recovery of $\mathrm{NMB}^{2-4}$ was still 2 decades away. Today's marketed NMBDs are noted for their hemodynamic stabilities, faster onsets, and more predictable recoveries. However, residual paralysis still remains a clinically significant problem.

\section{- Monitoring NMB}

An understanding of the methodology used to measure the depth of NMB is essential to clinically determine the suitability and timing of reversal and to provide the criteria necessary to confirm safe recovery from blockade.

The response of the adductor pollicis brevis muscle after stimulation of the ulnar nerve at the wrist with surface electrodes is the most common way to assess the degree of NMB in clinical practice. Four methods are currently used: mechanomyography (MMG), electromyography (EMG), acceleromyography (AMG), and direct palpation. MMG, a measurement of the force of contraction, and EMG, which measures the amplitude of the electrical signal of the muscle, are the research methods. AMG measures the isotonic acceleration of the adductor 
pollicis using a piezoelectric transducer. The basis of this method is that the acceleration of a muscle is directly proportional to its force of contraction. The major disadvantages of these techniques include the need for immobilization of the arm in an optimal position, which may not be possible during some surgical procedures, a limited availability of the MMG and EMG, and cost. At the current time, the AMG is the least expensive of the technologies used to objectively assess NMB. However, the acquisition price of $\$ 695.00$ for the most basic unit (personal communication, Bluestar Enterprises, Chanhassen, MN) may be considered prohibitive for the widespread use of this method in the operating room.

Direct palpation of the thumb to estimate both the force of isometric contraction and the force of acceleration evoked by ulnar nerve stimulation is the most common method used to assess NMB. Depending on the position of the patient, anesthesiologists have observed the contraction of the orbicularis oculi muscle, thumb, and great toe after stimulation of the facial, ulnar at the elbow, and posterior tibial nerves, respectively. As I will discuss below, these subjective observations are fraught with errors even in the hands of experienced clinicians.

\section{- Patterns of Nerve Stimulation}

Four patterns of stimuli to evoke muscle contraction are currently used. $^{5}$

The first pattern is the single twitch stimulus (Fig. 1). A single twitch is administered every 10 seconds $(0.1 \mathrm{~Hz})$ at a supramaximal stimulus. This supramaximal stimulus is a current that is slightly above that current at which a maximal twitch height is obtained. The degree of $\mathrm{NMB}$ is assessed by comparing the twitch height after the administration

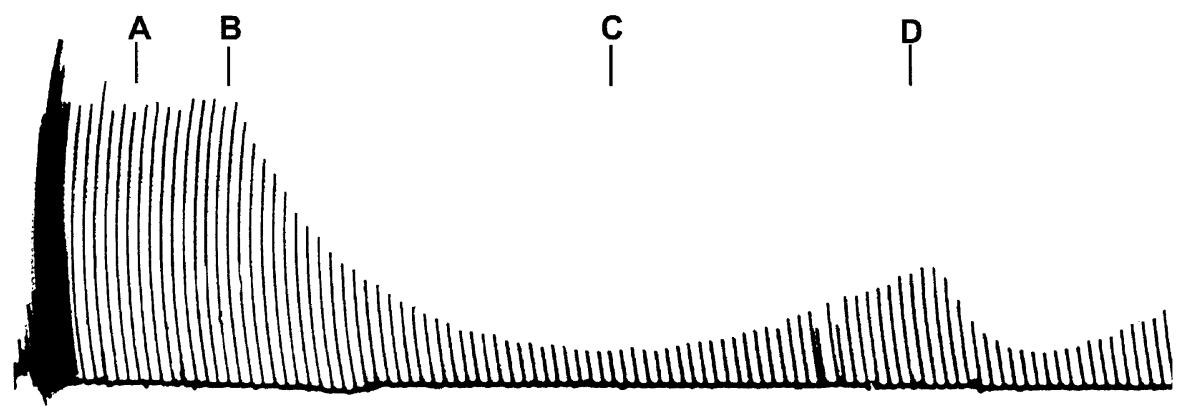

Figure 1. Single twitch stimuli. Maximal twitch height $(A)$ using supramaximal stimuli was established. After mivacurium $(0.25 \mathrm{mg} / \mathrm{kg}$ in divided dose) was administered (B), the twitch height decreased to a minimal height of $10 \%(C)$ followed by spontaneous recovery to $25 \%(D)$. Subsequent decrease in twitch height was noted after additional mivacurium was given. 


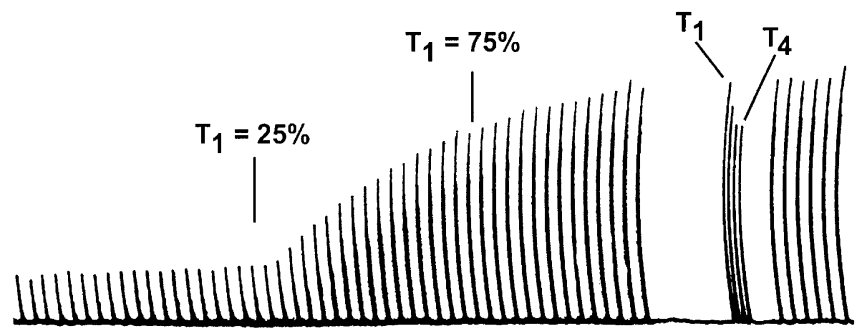

Figure 2. TOF. Spontaneous recovery from NMB with rocuronium $(1.2 \mathrm{mg} / \mathrm{kg})$ is demonstrable to a $T_{1}$ of $25 \%$ at which time neostigmine/glycopyrrolate was administered. $T_{1}=75 \%$ at 15 minutes after reversal. The TOF tracing at 22 minutes demonstrates at $T_{1}$ of $95 \%$ and a $T_{4}$ of $75 \%$ for a $T_{4} / T_{1}$ ratio of 0.8 .

of the NMBD with the control twitch height obtained before blockade. The response to single twitch stimuli monitored by MMG is the classic method to study the pharmacodynamics of the NMBD. ${ }^{6}$ For example, $95 \%$ effective dose $\mathrm{ED}_{95}$ of a neuromuscular blocker is that concentration at which the twitch height is depressed by $95 \%$ of maximal height. The shortcoming of this method is impracticality in routine clinical practice of establishing a baseline before the administration of the NMB.

With train-of-four (TOF) stimulation (Fig. 2), a pattern of 4 stimuli at $2 \mathrm{~Hz}$ is repeated every 10 to 12 seconds. ${ }^{7}$ With TOF, a comparison of the strength of the first twitch $\left(T_{1}\right) 2$ seconds later with that of the fourth twitch $\left(\mathrm{T}_{4}\right)$ eliminates the need for a control value. On the basis of comparisons with single twitch stimuli, 1, 2, or 3 twitches will be elicited when the strength of the first twitch is reduced to $90 \%, 80 \%$, and $75 \%$ of the control height, respectively. At a $\mathrm{T}_{4} / \mathrm{T}_{1}$ ratio of 0.75 ( 3 twitches), patients will be able to sustain a 5-second head lift, vital capacity of 15 to $20 \mathrm{~mL} / \mathrm{kg}$, an effective cough, and an inspiratory force of $-25 \mathrm{~cm} \mathrm{H}_{2} \mathrm{O}$.

When the response to TOF is absent, it is useful to determine whether the degree of NMB has a potential for reversal. The presence of TOF responses after tetanic stimulation at $50 \mathrm{~Hz}$ for 5 seconds is called posttetanic potentiation (Fig. 3). Instead of TOF, single twitches at

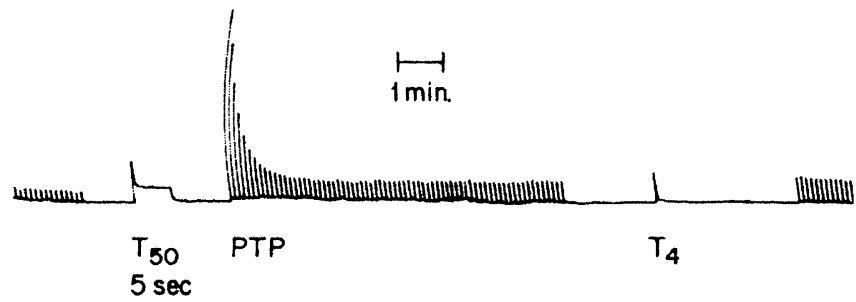

Figure 3. Posttetanic potentiation. At $T_{50}$ tetanic stimulation was applied for 5 seconds. There is marked posttetanic potentiation of the twitch that stabilizes at approximately twice the height of the pretetanic twitch. At $T_{4}$ TOF stimulation was started with only one response present. Reprinted with permission from Ali and Savarese. 


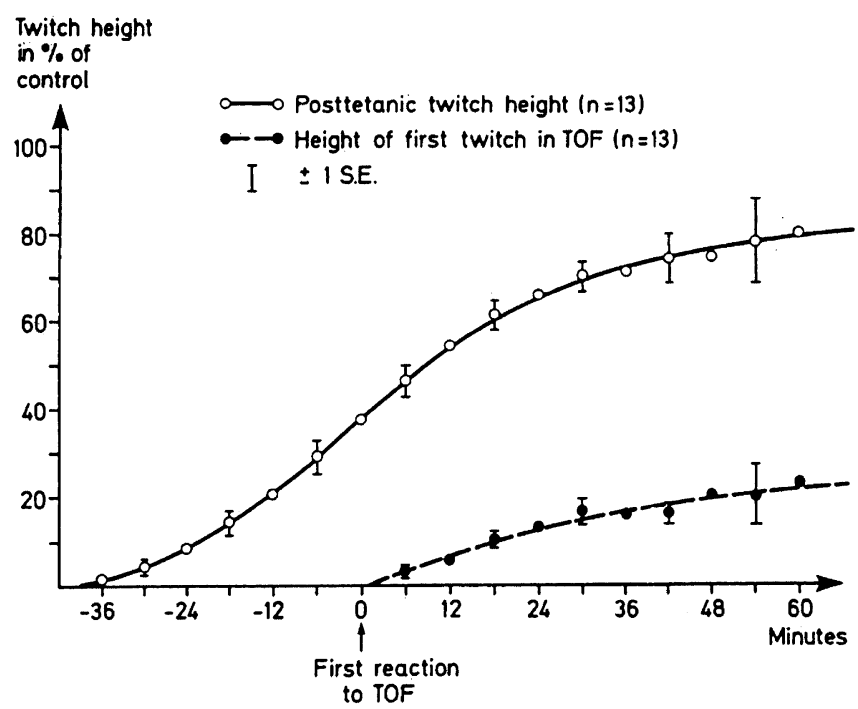

Figure 4. Relationship between the first posttetanic twitch height and TOF stimulation. The response to posttetanic twitch stimulation appears approximately 37 minutes before the first evidence of a response to the TOF. Reprinted with permission from Viby-Mogensen et al. ${ }^{8}$

$1 \mathrm{~Hz}$ can be applied 3 seconds after tetanic stimulation to obtain a posttetanic count (PTC; Fig. 4). A PTC of 10 coincides with the first twitch of the TOF, whereas a PTC of 1 indicates that the first twitch of the TOF should occur at approximately 30 minutes when pancuronium is used and at 8 minutes with vecuronium and atracurium. The absence of a posttetanic twitch indicates that the depth of the blockade is significantly pronounced and suggests that the administration of reversal agents will not probably be efficacious.

Double burst stimulation (Fig. 5) consists of 2 bursts of 3 stimuli at $50 \mathrm{~Hz}$ separated by $750 \mathrm{~ms}$. These sets of stimuli are close enough together to exhibit fade, which may be easier to detect than TOF when there is a partial blockade. In the absence of fade to double burst stimulation, there is a $90 \%$ chance that the TOF ratio is $\geq 0.6 .^{9}$

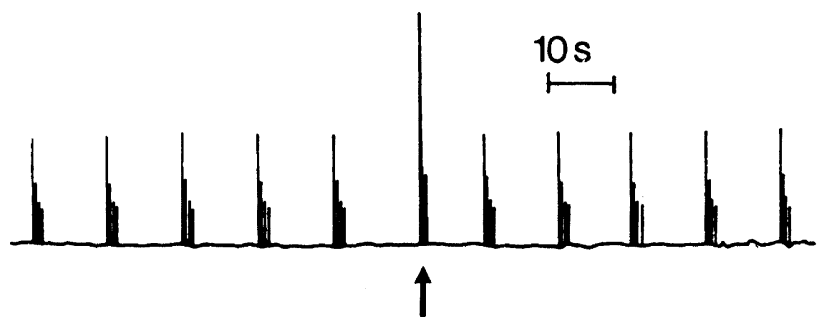

Figure 5. Twitch recording of the TOF and the double burst stimulus response (arrow). Although there is fade to both modes of stimulation, the first twitch with the double burst stimulation is greatly increased compared with the first twitch with TOF. Reprinted with permission from Drenck et al. 


\section{- Neuromuscular Blockers and Reversal of Activity ${ }^{\mathbf{1 0}}$}

Succinylcholine $(\mathrm{SCH})$ is the only nondepolarizing NMBD. It has a brief duration of action because most of it is degraded by butyrylcholinesterase (plasma cholinesterase) at approximately $80 \mathrm{mg}$ of SCH per minute before it reaches the motor endplate. The SCH that binds to the muscle motor endplate is resistant to the action of acetylcholinesterase; paralysis ends by the diffusion of SCH from the neuromuscular junction. The blockade with $\mathrm{SCH}$ is characterized by a lack of fade of tetanus, minimal fade on TOF, and no posttetanic facilitations. It is enhanced by anticholinesterase agents.

Prolonged NMB with SCH is usually due to either a genetic-based abnormality of pseudocholineasterase, an enzyme deficiency, or an overdose leading to a Phase II block. Approximately $0.04 \%$ of patients are homozygous for the 2 alleles of an atypical gene that controls the quantity and quality of plasma cholinesterase. These patients cannot metabolize SCH readily and experience a prolonged block. Most individuals $(96 \%)$ are homozygous for the normal gene, whereas $4 \%$ are heterozygous with 1 normal and 1 atypical gene. A clinical test used to assess these genetic differences uses the local anesthetic, dibucaine, which inhibits the activity of normal, but not of atypical, plasma cholinesterase. A dibucaine number of $>70$ (marked inhibition of the enzyme) indicates a normal pseudocholinesterase. Less than 30 reveals homozygosity for the atypical enzyme. Heterozygotes have dibucaine numbers between these values. Two rare genes may code for either a fluoride-resistant enzyme with marked decrease in metabolism of SCH or an enzyme that is incapable of metabolizing SCH (silent gene).

Decreased amounts of plasma cholinesterase that cause prolonged responses to $\mathrm{SCH}$ are seen occasionally in patients with severe liver disease and in peripartum patients. Inhibition of plasma cholinesterase by echothiopate eyedrops, anticholinesterases, organophosphate insecticides, hexafluorenium, phenelzine, and some cytotoxic tumor agents also prolongs the duration of $\mathrm{SCH}$.

When the dose of $\mathrm{SCH}$ is excessive, for example, with muscle paralysis maintained with an infusion of $\mathrm{SCH}$, the blockade resembles that seen with nondepolarizing NMBD. This "Phase II block" is characterized by a marked fade of both tetanus and TOF, posttetanic potentiation, prolonged recovery, and the ability to reverse with anticholinesterases once plasma levels of SCH have been allowed to decrease.

The remainder of the NMBDs are nondepolarizing drugs. The most common properties of these are presented in Table 1 . The metabolism of these compounds will affect the recovery of NMB.

Mivacurium is a short-acting benzylisoquinoline and the only nondepolarizing drug metabolized by plasma cholinesterase in a 
Table 1. Nondepolarizing Neuromuscular Blockers

\begin{tabular}{|c|c|c|c|c|c|c|c|c|c|}
\hline Drug & $\begin{array}{l}\text { Trade } \\
\text { Name }\end{array}$ & $\begin{array}{l}\text { Chemical } \\
\text { Structure* }\end{array}$ & $\begin{array}{c}\text { Duration of } \\
\text { Action } \dagger\end{array}$ & $\begin{array}{c}\text { Active } \\
\text { Metabolite }\end{array}$ & $\begin{array}{c}\mathrm{ED}_{95} \\
(\mathrm{mg} / \mathrm{kg})\end{array}$ & $\begin{array}{c}\text { Intubation } \\
\text { Dose } \\
(\mathrm{mg} / \mathrm{kg})\end{array}$ & $\begin{array}{c}\text { Time to } \\
\text { Maximum } \\
\text { Block (min) }\end{array}$ & $\begin{array}{l}\text { Time to } \\
25 \% \\
\text { Recovery } \\
(\mathrm{min})\end{array}$ & $\begin{array}{c}\text { Time to } \\
95 \% \\
\text { Recovery } \\
\text { (min) }\end{array}$ \\
\hline Cisatracurium & Nimbex & B & I & no & 0.05 & 0.2 & 2.5 & $66-71$ & $83-91$ \\
\hline Mivacurium & Mivacron & B & S & no & 0.08 & $0.15+0.1 \ddagger$ & $1.5-2$ & 23 & 34 \\
\hline Pancuronium & Pavulon & S & $\mathrm{L}$ & yes & 0.07 & $0.08-0.10$ & $2-3$ & $90-100$ & $120-150$ \\
\hline Rocuronium & Zemuron & S & $\mathrm{L}$ & no & 0.03 & 1.2 & 1 & $38-150$ & $\S$ \\
\hline Vecuronium & Norcuron & S & I & yes & 0.05 & $0.08-0.10$ & $2-3$ & $45-60$ & $60-80$ \\
\hline
\end{tabular}

*B indicates benzylisoquinoline; $\mathrm{S}$, aminosteroid.

$\dagger \mathrm{I}$ indicates intermediate; L, long; S, short.

\$Divided dosing: $0.15 \mathrm{mg} / \mathrm{kg}$ followed at $30 \mathrm{~s}$ with $0.1 \mathrm{mg} / \mathrm{kg}$.

$\S$ No reports for this dose to $95 \%$ spontaneous recovery. 
manner similar to that of SCH. Reversal of mivacurium with neostigmine may actually slow its recovery. If a deep blockade is manifested by no or only 1 twitch response to TOF stimulation, neostigmine and, to a much lesser extent, edrophonium may slow the hydrolysis of mivacurium for 20 to 60 minutes. This effect may be exaggerated in someone with low levels of plasma cholineasterase, which may inhibit the ability of plasma cholinesterase to metabolize mivacurium. Therefore, before attempting an anticholinesterase-induced reversal of mivacurium, there should first be evidence that recovery is spontaneously occurring as is indicated by a minimum of at least 2 twitches in response to TOF.

The benzylisoquinoline, atracurium, is a compound that was intentionally synthesized to degrade. It undergoes spontaneous degradation at physiologic temperature and $\mathrm{pH}$ by the Hofmann elimination reaction, and metabolism by nonspecific plasma esterases. In a similar fashion, cisatracurium, the cis isomer of atracurium, is degraded by Hofmann elimination. However, it is not degraded by an esterase. Because the termination of these 2 drugs is independent of liver and kidney function, the recovery of muscle activity is unaltered in renal failure, hepatic failure, in infants and children, in the elderly, after continuous infusion, and after repeated administration of bolus doses.

The aminosteroids, in contrast to the benzylisoquinolines, depend on organ elimination for the termination of activity. Vecuronium is excreted mostly as unchanged drug in the bile and its elimination can be prolonged in patients with liver disease. It is also metabolized in the liver to 3-desacetyl, 17-desacetyl, and 3,17-desacetylvecuronium. 3-desacetylvecuronium is about half as potent as the parent compound and is eliminated by the kidneys, which may account for occasional reports of somewhat prolonged blockade when vecuronium is given as a continuous infusion to facilitate ventilation of patients in the intensive care unit with compromised renal function. There is an increase in recovery times in infants aged less than 1 year, because of an increased sensitivity to vecuronium, a larger volume of distribution, and a decreased clearance of the drug.

Rocuronium is a derivative of vecuronium that was developed to have a rapid onset of action. Its rapid uptake by the liver because of its relative lipophilicity, subsequent excretion into the bile, and rapid redistribution from the neuromuscular junction contribute to its intermediate duration of action at lower doses. Because rocuronium depends on organs of elimination for its termination of action, its clinical duration at escalating doses is dose-related. At $\mathrm{ED}_{95}$ multiples of 2, 3, and 4 times, expected durations to $25 \%$ recovery are 37,53 , and 73 minutes with wide variability. Unchanged rocuronium has been found in the urine $(8.7 \%)$ and in the bile $(>50 \%)$ and its pharmacokinetics have been reported to be altered in those with major renal and hepatic 
diseases. Altered pharmacokinetics and prolonged duration of action have been shown in both infants and the elderly.

Pancuronium, the oldest of all the aminosteroids, is predominantly eliminated by the kidneys and has a decreased clearance and a prolonged duration of action with renal insufficiency. In elderly patients its clearance is reduced, which prolongs the duration of action. About $10 \%$ to $20 \%$ of the injected dose of pancuronium is metabolized in the liver to 3 metabolites: 3-hydroxypancuronium, 17-hydroxypancuronium, and 3,17-dihydroxypancuronium. The 3-hydroxy metabolite is renally excreted and, similar to the vecuronium metabolite, possesses neuromuscular blocking activity that is about half as potent as the parent compound.

\section{- TOF Ratios and Residual NMB}

Residual NMB has been frequently observed in patients admitted to post anesthesia care units (PACUs) who do not have alterations in plasma cholinesterase, have normal organ function, and do not manifest a paraneoplastic syndrome. ${ }^{11}$ Determination of the presence of this residual NMB is critical for patient safety.

What can be considered as adequate reversal? In the early 1970s, Ali and coworkers ${ }^{2-4}$ first published the use of TOF to monitor NMB. Their study ${ }^{3}$ clearly showed that the muscle weakness was presented with TOF ratios $<0.6$, that is, the height of the fourth twitches was less than $60 \%$ of the first twitches in the train. They ${ }^{7-12}$ subsequently demonstrated that a TOF ratio of 0.7 was a sensitive and reliable indicator for the return of sufficient muscular function to permit endotracheal extubation.

Although recovery to a TOF ratio of 0.7 may indicate adequate muscle strength, it is desirable to achieve a greater degree of reversal. Eriksson et $\mathrm{al}^{13}$ studied pharyngeal function at rest and during swallowing in partially paralyzed subjects. Aspiration was evident in 6 of the 14 subjects with TOF ratios $<0.9$, whereas there was no aspiration occurring with recovery to TOF ratios $\geq 0.9$. The upper esophageal sphincter tone was reduced below TOF ratios of 0.9 (Fig. 6) with decreased muscle coordination seen at TOF ratios $<0.6$. In a similar study, nonanesthetized subjects were kept at TOF ratios 0.65 to 0.75 and 0.85 to 0.90 with mivacurium. ${ }^{14}$ Although a drawback of this study was that supramaximal stimuli were not employed, at TOF ratios $<0.9$, subjects did exhibit diplopia and difficulty tracking moving objects. Interestingly, several of the subjects complained of diplopia for greater than one hour after the return of TOF to 1.0. Grip strength measured with a dynamometer was $50-75 \%$ of control values, and there was decreased jaws strength with TOF ratios $<0.85$. None of the patients, however, had difficulty maintaining an airway. 


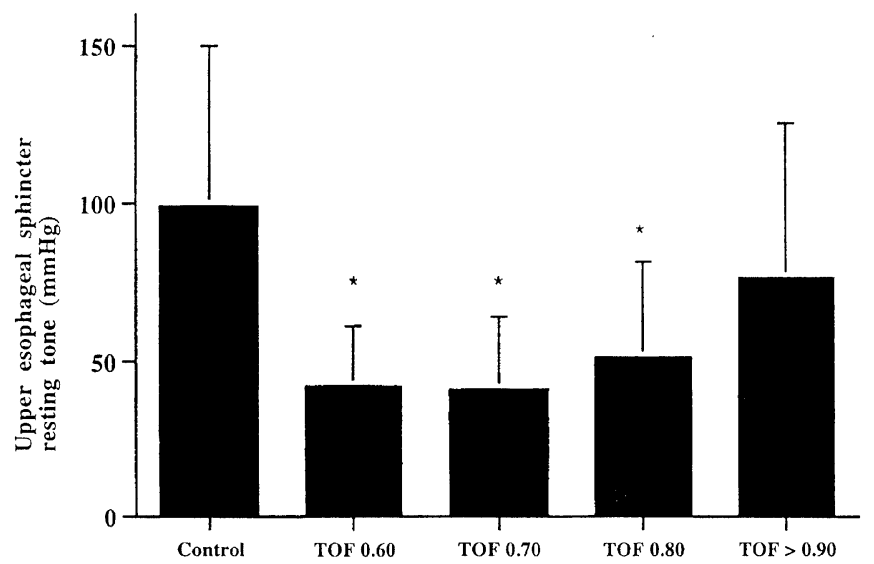

Figure 6. Upper esophageal sphincter muscle tone $(\mathrm{mm} \mathrm{Hg})$ during partial paralysis in awake volunteers versus mean $\pm S D$ vecuronium-induced TOF ratios. Reprinted with permission from Eriksson et al. ${ }^{13}$

Several factors may influence the assessment of NMB. The most basic is the application of surface electrodes. It is common practice for investigators to clean and lightly abrade the skin before placing surface electrodes over the desired nerve to be stimulated. In clinical practice, most of us have observed that this preparation is not usually carried out. Thus, the applied stimuli may be suboptimal. Even with properly placed electrodes, 9 of 19 patients with wrists $>16 \mathrm{~cm}$ in circumference required currents in excess of $40 \mathrm{~mA}$ to achieve supramaximal stimuli. ${ }^{15}$

Finally, although most investigators have used objective TOF measurements to examine the depth of $\mathrm{NMB}$, the subjective palpation of the thumb is still the most common clinically used assessment. VibyMogensen et $\mathrm{al}^{16}$ demonstrated that the palpation was not accurate even for clinicians experienced with monitoring the depth of NMB (Fig. 7). In some instances, a TOF ratio of 0.41 to 0.50 was judged to have adequate recovery in only one third of the observations. Others either could not detect fade when the TOF ratio was as low as 0.30 to 0.40 or indicated that fade was present with a TOF ratio of 0.9 to $0.95 .{ }^{16}$ The AMG may be an attractive alternative for the routine objective assessment of NMB. ${ }^{17,18}$ However, until this methodology is considered cost-effective palpation of the thumb in concert with TOF stimulation remains the routine method for monitoring $\mathrm{NMB}$ in clinical practice.

\section{- Recurarization}

When NMBD use initially began, the question arose whether patients could be reparalyzed after the seemingly adequate reversal of 


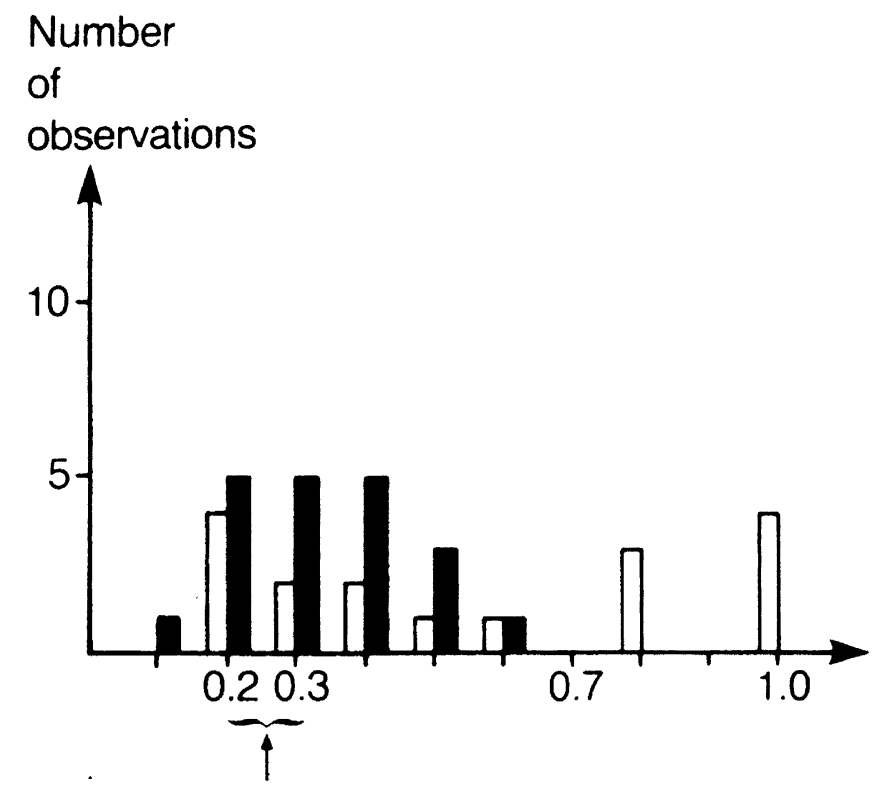

Figure 7. Results of manual estimations of TOF by moderately experience observers (open bars) and very experienced observers (solid bars). The true TOF ratio (arrow) was measured with MMG. Note the wide scatter in estimated ratios. Reprinted with permission from Viby-Mogensen et al. ${ }^{16}$

the NMB. This was termed "recurarization." For example, spontaneous recovery of curare to $90 \%$ of control muscle activity was reached in 267 minutes as assessed with tetanic stimulation and MMG. ${ }^{19}$

After the administration of neostigmine after a return to $10 \%$ recovery (126 min), 90\% recovery was attained within 2 to 14 minutes. However, 5 patients were unable to sustain tetanic contraction and $2 \mathrm{had}$ nonsustained tetanus after 30 minutes. Recurarization is clearly a misnomer: it is the failure to adequately reverse the action of NMBD. However, the use of the term still persists.

\section{- Residual Neuromusclar Blockade in the PACU}

In the absence of intraoperative monitoring $\mathrm{NMB}$ produced with pancuronium or curare, $42 \%$ of patients had TOF ratios of $<0.70$, whereas $22 \%$ of these were $<0.6$ upon arrival in the PACU. ${ }^{20}$ Shorten et $\mathrm{al}^{21}$ examined residual curarization after the administration and reversal of pancuronium based on either clinical criteria (muscle movement, spontaneous respirations) or TOF. Twenty minutes after reversal, residual paralysis was observed in $47 \%$ of the empirically treated patients and $15 \%$ of those monitored with TOF. 
There is an impressive body of literature that demonstrates residual $\mathrm{NMB}$ in the immediate postoperative condition even with the use of intraoperative monitoring. A major focus of studies has been the comparison of pancuronium with the intermediate muscle relaxants. Patients who received pancuronium or vecuronium were monitored with TOF, and were considered as adequately reversed in the operating room, and were further examined in the PACU with TOF. ${ }^{22}$ With the caveat that submaximal stimuli were used, $48 \%$ of the pancuronium and $8 \%$ of the vecuronium patients had TOF ratios $<0.7$ at 15 minutes after admission to the PACU. Murphy et $\mathrm{al}^{23}$ randomized orthopedic surgery patients to receive pancuronium or rocuronium. In the PACU, $40 \%$ of the patients who had received pancuronium had TOF ratios $<0.7$ compared with $5.9 \%$ of the rocuronium patients. In this study, and most of the other studies employing rocuronium, ${ }^{18-25}$ the doses used were in the lower range, comparable to the effects of vecuronium, rather than in the higher range used for rapid sequence inductions. ${ }^{26}$ In our hands (unpublished observations), rocuronium at 0.9 and $1.2 \mathrm{mg} / \mathrm{kg}$ has a recovery that is similar to pancuronium but with a higher degree of variability.

In a retrospective study of 270 patients after the administration of NMB, Ballantyne and Chang $^{27}$ reported that the adjusted mean recovery times between patients receiving mivacurium, atracurium, or vecuronium compared with pancuronium were shortened by 30 minutes. They extrapolated an offset in the cost of vecuronium versus a higher cost related to the longer PACU stay when pancuronium was employed. The latter might have been a sequella of residual NMB. In contrast, in the same year, Freund et $\mathrm{al}^{28}$ published results of their outcome project in which pancuronium was used as the NMBD with vecuronium restricted by a departmental guideline. They concluded that their data did not support a difference in clinical outcome using pancuronium, although a greater margin of safety was possible with intermediate NMBD such as vecuronium. One should be skeptical of this study because the presence of residual NMB was not examined.

It is intuitive that the intermediate neuromuscular blockers should have properties that minimize residual NMB. This may not be true in practice, however. Of the 150 patients who received vecuronium, atracurium, or rocuronium, TOF ratios $<0.8$ were found in $64 \%$, $52 \%$, and $39 \%$ of PACU patients, respectively. ${ }^{29}$ The mean times (minutes) to achieve TOF ratios $>0.8$ after arrival were 9.2 for vecuronium, 6.9 for atracurium, and 14.7 for rocuronium, respectively. Forty-nine percent of these patients who exhibited NMB were reversed before the arrival in the PACU. In another study, 40 subjects were administered cisatracurium or rocuronium. ${ }^{25}$ Five exhibited TOF ratios $<0.720$ minutes after reversal and only 11 patients recovered to TOF ratios $>0.9$. 


\section{- Timing of Anticholinesterase Administration}

The timing of the administration of anticholinesterases may be one contributing factor to residual NMB. After a deep block with vecuronium was established, an initial neostigmine dose was administered, followed by a second dose when a first twitch appeared at $10 \%$ of the control height. ${ }^{30}$ Reversal of the NMB took approximately 60 to 80 minutes. Kirkegaard and coinvestigators ${ }^{31}$ found that 3 or 4 tactile responses should be present at the time of neostigmine administration to achieve a reversal of NMB to a TOF ration of 0.7 in $>87 \%$ of patients. The goal of a TOF ratio of 0.9 was not attained in all patients even at 20 to 30 minutes. In a similar study, ${ }^{25} 20$ minutes after reversal from a twitch height of $5 \%$, only 11 of 40 patients recovered to a TOF ratio of 0.9 .

\section{- New Advances in the Reversal of Neuromuscular Blockers}

An exciting alternative to the reversal of NMB with anticholinesterases is by binding the NMBD in a form that will not interact with the neuromuscular junction. Org 25969 is a $\gamma$-cyclodextrin that forms a tight complex with rocuronium. ${ }^{32}$ Anesthetized guinea pigs were given a bolus of rocuronium with continued paralysis maintained with an infusion. After 30 minutes of continued NMB, an infusion of Org 25969 was started while the rocuronium infusion continued. The NMB was reversed in the presence of an increase in the total plasma concentration of rocuronium that was a reflexion of bound and free drug. ${ }^{32}$ In a study of 29 healthy volunteers, Org 25969 was administered 3 minutes after $0.6 \mathrm{mg} / \mathrm{kg}$ rocuronium. ${ }^{33}$ At the highest dose studied, $8 \mathrm{mg} / \mathrm{kg}$, Org 25969 affected a return of TOF ratio to 0.9 within 2 minutes. Although Org 25969 is specific for rocuronium (and vecuronium), the synthesis of molecules with specific binding for each NMBD would markedly reduce the incidence of residual NMB.

\section{- Conclusion}

Each decade since the introduction of neuromuscular blockers, there has been a call for vigilant, objective monitoring to prevent postoperative residual paralysis. ${ }^{3,4,7,34,35}$ As best stated by Bevan et al, ${ }^{34}$ "If the purpose of reversal of neuromuscular blocking drugs is to restore neuromuscular activity, then the presence of detectable weakness represents therapeutic failure." It is hoped that I have made the reader more aware that multiple studies from many countries have confirmed that residual NMB is still a major issue in anesthetic care. Until better drugs are available, whether the goal of a return of TOF ratio to 0.7 or 0.9 
is attained, the basic principles of the attention to the depth and recovery of NMB put forth over 30 years ago steadfastly remain. ${ }^{36}$

\section{- References}

1. Beecher H, Todd D. A study of the deaths associated with anesthesia and surgery. Am J Surg. 1954;140:2-34.

2. Ali HH, Utting JE, Nightingale DA, et al. Quantitative assessment of residualcurarization in humans. Br J Anaesth. 1970;42:802-803.

3. Ali HH, Utting JE, Gray TC. Quantitative assessment of residual antidepolarizing block. II. Br J Anaesth. 1971;43:478-485.

4. Ali HH, Utting JE, Gray TC. Quantitative assessment of residual antidepolarizing block. I. Br J Anaesth. 1971;43:473-477.

5. Ali HH, Savarese JJ. Monitoring of neuromuscular function. Anesthesiology. 1976;45:216-249.

6. Savarese JJ, Belmont MR, Hashim MA, et al. Preclinical pharmacology of GW280430A (AV430A) in the rhesus monkey and in the cat: a comparison with mivacurium. Anesthesiology. 2004;100:835-845.

7. Ali HH, Savarese JJ, Lebowitz PW, et al. Twitch, tetanus and train-of-fours indices of recovery from nondepolarizing neuromuscular blockade. Anesthesiology. 1981; 54:294-297.

8. Viby-Mogensen J, Howardy-Hansen P, Chraemmer-Jorgensen B, et al. Posttetanic count (PTC): a new method of evaluating an intensenondepolarizing neuromuscular blockade. Anesthesiology. 1981;55:458-461.

9. Drenck NE, Ueda N, Olsen NV, et al. Manual evaluation of residual curarization using double burst stimulation: a comparison with train-of-four. Anesthesiology. 1989;70:578-581.

10. Pino RM, Basta SJ. Pharmacology of Neuromuscular Blocking Drugs. 2nd ed. St Louis: Mosby; 1998.

11. Small S, Ali HH, Lennon VA, et al. Anesthesia for an unsuspected Lambert-Eaton myasthenic syndrome with autoantibodies and occult small cell lung carcinoma. Anesthesiology. 1992;76:142-145.

12. Brand J, Cullen D, Wilson NE, et al. Spontaneous recovery from nondepolarizing neuromuscular blockade: correlation between clinical and evoked response. Anesth Analg. 1977;56:55-58.

13. Eriksson LI, Sundman E, Olsson R, et al. Functional assessment of the pharynx at rest and during swallowing in partially paralyzed humans: simultaneous videomanometry and mechanomyography of awake human volunteers. Anesthesiology. 1997;87: 1035-1043.

14. Kopman A, Yee P, Neuman G. Relationship of the train-of-four fade ration to clinical signs and symptoms of residual paralysis in awake volunteers. Anesthesiology. 1997;86:761-765.

15. Kopman A, Lawson D. Milliamperage requirements for supramaximal stimulation of the ulnar nerve with surface electrodes. Anesthesiology. 1984;61:83-85.

16. Viby-Mogensen J, Jensen NH, Engbaek J, et al. Tactile and visual evaluation of the response to train-of-four nerve stimulation. Anesthesiology. 1985;63:440-443.

17. Samet A, Capron F, Alia F, et al. Single acceleromyographic train-of-four, 100-Hertz tetanus or double-burst stimulation: which test performs better to detect residual paralysis? Anesthesiology. 2005;102:51-56.

18. Gatke MR, Viby-Mogensen J, Rosenstock C, et al. Postoperative muscle paralysis after rocuronium: less residual block when acceleromyography is used. Acta Anaesthesiol Scand. 2002;46:207-213. 
19. Walts L, Thorpe W, Dillon J. Recurarization-fact or fiction. Anesth Analg. 1971;50: 879-884.

20. Viby-Mogensen J, Jorgensen BC, Ording H. Residual curarization in the recovery room. Anesthesiology. 1979;50:539-541.

21. Shorten GD, Merk H, Sieber T. Perioperative train-of-four monitoring and residual curarization. Can J Anaesth. 1995;42:711-715.

22. Brull SJ, Ehrenwerth J, Connelly NR, et al. Assessment of residual curarization using low-current stimulation. Can J Anaesth. 1991;38:164-168.

23. Murphy GS, Szokol JW, Franklin M, et al. Postanesthesia care unit recovery times and neuromuscular blocking drugs: a prospective study of orthopedic surgical patients randomized to receive pancuronium or rocuronium. Anesth Analg. 2004;98:193-200, Table of contents.

24. Debaene B, Plaud B, Dilly MP, et al. Residual paralysis in the PACU after a single intubating dose of nondepolarizing muscle relaxant with an intermediate duration of action. Anesthesiology. 2003;98:1042-1048.

25. Kopman AF, Kopman DJ, Ng J, et al. Antagonism of profound cisatracurium and rocuronium block: the role of objective assessment of neuromuscular function. J Clin Anesth. 2005;17:30-35.

26. Magorian T, Flannery KB, Miller RD. Comparison of rocuronium, succinylcholine, and vecuronium for rapid-sequence induction of anesthesia in adult patients. Anesthesiology. 1993;79:913-918.

27. Ballantyne JC, Chang Y. The impact of choice of muscle relaxant on postoperative recovery time: a retrospective study. Anesth Analg. 1997;85:476-482.

28. Freund PR, Bowdle TA, Posner KL, et al. Cost-effective reduction of neuromuscularblocking drug expenditures. Anesthesiology. 1997;87:1044-1049.

29. Hayes AH, Mirakhur RK, Breslin DS, et al. Postoperative residual block after intermediate-acting neuromuscular blocking drugs. Anaesthesia. 2001;56:312-318.

30. Magorian TT, Lynam DP, Caldwell JE, et al. Can early administration of neostigmine, in single or repeated doses, alter the course of neuromuscular recovery from avecuronium-induced neuromuscular blockade? Anesthesiology. 1990;73:410-414.

31. Kirkegaard H, Heier T, Caldwell JE. Efficacy of tactile-guided reversal from cisatracurium-induced neuromuscular block. Anesthesiology. 2002;96:45-50.

32. Epemolu O, Bom A, Hope F, et al. Reversal of neuromuscular blockade and simultaneous increase in plasma rocuronium concentration after the intravenous infusion of the novel reversal agent Org 25969. Anesthesiology. 2003;99:632-637, Discussion 6A.

33. Gijsenbergh F, Ramael S, Houwing N, et al. First human exposure of Org 25969, a novel agent to reverse the action of rocuronium bromide. Anesthesiology. 2005;103: 695-703.

34. Bevan DR, Smith CE, Donati F. Postoperative neuromuscular blockade: a comparison between atracurium, vecuronium, and pancuronium. Anesthesiology. 1988;69: 272-276.

35. Eriksson LI. Evidence-based practice and neuromuscular monitoring: it's time for routine quantitative assessment. Anesthesiology. 2003;98:1037-1039.

36. Ali HH. Criteria of adequate clinical recovery from neuromuscular block. Anesthesiology. 2003;98:1278-1280. 